\title{
Interpregnancy interval and the risk of preterm birth: a case-control study of infants born at Al-sadaqa general teaching hospital, Aden, Yemen
}

\author{
Aidroos Z. Bukair ${ }^{1,2}$ Abdul-Wahab M. Al-Saqladi ${ }^{1,2}$, Aida H. Al-Sadeeq ${ }^{2}$ \\ ${ }^{1}$ Department of Paediatric, Faculty of Medicine and Health Sciences, University of Aden, Yemen \\ ${ }^{2}$ Department of Paediatric, Al-Sadaqa General Teaching Hospital, Aden , Yemen
}

Received: 15 February 2016

Accepted: 11 March 2016

*Correspondence:

Dr. Abdul-Wahab M. Al-Saqladi,

E-mail: asaqladi@yahoo.com

Copyright: $\odot$ the author(s), publisher and licensee Medip Academy. This is an open-access article distributed under the terms of the Creative Commons Attribution Non-Commercial License, which permits unrestricted non-commercial use, distribution, and reproduction in any medium, provided the original work is properly cited.

\begin{abstract}
Background: Interpregnancy interval (IPI) is a known risk factor for preterm birth. The aim of this study was to assess the relationship between IPI and spontaneous preterm birth, and to identify the influence of confounding variables such as socioeconomic status, maternal age, and reproductive history.

Methods: This is a hospital-based, case-control study conducted in the department of neonatology, Al-Sadaqa General Teaching Hospital, Aden, during June to September 2011. A case was defined as infant born spontaneously before 37 weeks of gestation and control was a next eligible infant born between 37-42 complete weeks of gestation. Comparison between groups was assessed by statistical analysis and odds ratio were calculated for confounding factors.

Results: A total of 100 preterm (cases) and 100 full-term (controls) infants were evaluated for the effects of IPI. Intervals of both $<12$ months and $12-<24$ months were significantly associated with preterm births compared to control (37\% vs $12 \%$ and $73 \%$ vs $46 \%$ respectively, all $\mathrm{p}<0.05$ ). The risk of preterm birth was higher in association with low number of antenatal care visits $(\mathrm{OR}=10,95 \% \mathrm{CI}=1.62-61.46, \mathrm{p}=0.018)$, younger women's age $(\mathrm{OR}=8,95 \%$ $\mathrm{CI}=1.35-8.4, \mathrm{p}=0.001)$, non-educated mother $(\mathrm{OR}=7.92,95 \% \mathrm{CI}=2.49-25.22, \mathrm{p}=0.002)$ and gravid $2-3(\mathrm{OR}=6.5,95 \%$ $\mathrm{CI}=5.06-53.8, \mathrm{p}=0.001)$. Significant risk was also observed among mother with low socio-economic status and residents of rural areas (all $\mathrm{p}<0.05$ ).

Conclusions: Short IPI is significant risk factors for preterm birth. This highlights the importance of counseling women in childbearing age to wait at least 24 months between delivery and subsequent conception.
\end{abstract}

Keywords: Interpregnancy interval, Preterm birth, Birth spacing, Risk factor

\section{INTRODUCTION}

Preterm birth (PTB) is defined as a birth occurring before complete 37 weeks of gestation with worldwide estimates of 15 million preterm births each year. ${ }^{1}$ The global burden of PTB is varied with higher rate and poor outcomes in low and middle income countries. ${ }^{2}$ Prematurity is the leading cause of perinatal mortality, and the second most common cause of death in children under 5 years of age. ${ }^{3}$
Born prematurely are more likely to have several complications soon after birth and lifelong disabilities that impose a significant economic burden on both family, society and the health system. ${ }^{4}$ As most preterm births happen spontaneously the exact cause is still unsolved, a search for more predictive and reliable risk factors that may lead to effective intervention strategies are relevant to public health and should be of great interest for both general public and health professionals. $^{5,6}$ 
Interpregnancy interval (IPI) is a period of time between the end of one pregnancy and the conception of the next pregnancy. Numerous studies have shown relationship between short IPI and spontaneous preterm birth and IPI has been viewed as an important and modifiable risk factor for adverse birth outcomes, including preterm birth. ${ }^{7-12}$ Likewise, long interpregnancy intervals might also be important determinant of preterm birth, but fewer studies have analysed the relationship between long intervals and prematurity. ${ }^{7,13}$

The underline mechanism of short IPI on adverse birth outcomes are not well known, but has been attributed to maternal nutritional depletion, of particular interest is folate deficiency. ${ }^{14,15}$ This theory assumed that mothers with short birth spacing have insufficient time to replete the nutritional reserve necessary to fetal support. This seems to be important especially for those women with lifelong poverty and inadequate diet which lead to persistent marginalized nutritional status. Other assumption is that with short IPI postpartum stress and uterine inflammatory status have insufficient time for complete resolution and recovery.,16

According to WHO recommendation, waiting at least 24 months after a live birth before attempting subsequent pregnancy is likely to be beneficial for both mother and child health. ${ }^{11}$

Little is known about the effect of IPI on preterm delivery in developing countries particularly those with high fertility rate and low resource settings like Yemen and prior to this no study was conducted in this locality. The aim of the present study is to assess the relationship between interpregnancy interval and spontaneous preterm birth, and to identify the influence of associated variables such as socioeconomic status, maternal age and reproductive history.

\section{METHODS}

This is a hospital-based, case control study conducted in the department of neonatology, Al-Sadaqa General Teaching Hospital, Aden during June to September 2011. This hospital is a major referral hospital for women and children in Aden, and the neighbouring governorate and servicing both the urban and the adjacent rural areas.

\section{Definitions}

A case was defined as a singleton neonate who was born spontaneously before 37 week of gestation to a healthy Yemeni woman with no obstetric or medical complications, and whose previous pregnancy outcome was a full term live birth. The gestational age estimation was based on all available evidence at the time of birth, including prenatal record, date of last menstrual period and results of ultrasound evaluation. For each case, a control was selected with same eligibility criteria except a birth after 37-42 completed weeks of gestation. Twin and post term ( $\geq 42$ weeks) births were excluded.

We defined IPI as the interval between delivery of a live birth of previous pregnancy and the birth of the current child minus the duration of the index pregnancy. Gestational age was estimated as the number of completed weeks of gestation based on last menstrual period or calculated from ultrasound evaluation. IPI was categorized into 4 groups: less than 12, 12 to 23,24 to 59 , and 60 months or longer.

Maternal age was defined as completed years at time of index birth. Gravid was defined as the number of previous pregnancy after completing 28 weeks of gestation including still birth.

\section{Data collection}

Detailed medical and obstetric histories were collected for each case from the mother/relatives besides the infant and review of all available documents. Medical records of the patients were also evaluated. Data were extracted using pre-structured questionnaire, which included maternal age, residence, educational level, parity, antenatal care visits, and family income.

There were 42 cases and controls excluded due to inadequate information about gestational age and interpregnancy intervals, primarily because of uncertainty regarding the last menstrual period and/or ultrasound examination was not done.

Agreement of all participants (mother/guardian) to enroll had been asked.

\section{Data analysis}

The data were analysed using SPSS 21 program. Cases and controls were assessed for comparability on all the variables collected. Appropriate statistical tests were applied and $\mathrm{p}<0.05$ considered significant. The odds ratio with the $95 \%$ confidence interval were calculated for lower IPI compared to the assumed ideal IPI (of 24 months and more) as a refer group.

\section{RESULTS}

Table 1: Distribution of cases/controls by various interpregnancy intervals.

\begin{tabular}{|llll|}
\hline $\begin{array}{l}\text { Birth } \\
\text { interval }\end{array}$ & $\begin{array}{l}\text { Preterm } \\
\text { (cases), } \\
n=100\end{array}$ & $\begin{array}{l}\text { Full } \\
\text { term(control), } \\
\mathrm{n}=\mathbf{1 0 0}\end{array}$ & P value* \\
\hline$<12$ mo & 37 & 12 & 0.001 \\
\hline $12-23$ mo & 36 & 34 & 0.81 \\
\hline $24-59$ mo & 13 & 37 & 0.001 \\
\hline$\geq 60$ mo & 14 & 17 & 0.6 \\
\hline
\end{tabular}

*Chi square test 
A total of 100 preterm neonates were met the eligibility criteria, and consecutive 100 full term act as controls. Less than 12 months IPI was noted among $37 \%$ of preterm and $12 \%$ of controls $(\mathrm{p}<0.001)$.Comparing all those $<24$ months IPI, there were $73 \%$ preterm vs $48 \%$ full term infants $(\mathrm{p}<0.01)$ (Table 1, Figure 1).
According to WHO reference 24-59 months IPI as optimal birth spacing we considered this band as a referent group, which was identified among $13 \%$ and $37 \%$ of cases and controls respectively. Our results showed that IPI of $\geq 60$ months was not associated with increased proportion of preterm births $(\mathrm{p}>0.6)$.

Table 2: Distribution of selected maternal characteristics by interpregnancy interval.

\begin{tabular}{|c|c|c|c|c|c|c|c|c|}
\hline \multirow{3}{*}{ Variables } & \multicolumn{4}{|c|}{ Case (preterm), $\mathbf{n}=\mathbf{1 0 0}$} & \multicolumn{4}{|c|}{ Control (full term), $\mathrm{n}=\mathbf{1 0 0}$} \\
\hline & $<12$ mo & $12-23 \mathrm{mo}$ & $24-59 \mathrm{mo}$ & $\geq 60 \mathrm{mo}$ & $<12 \mathrm{mo}$ & $12-23 \mathrm{mo}$ & $24-59 \mathrm{mo}$ & $\geq 60 \mathrm{mo}$ \\
\hline & $\mathrm{n}=37$ & $\mathrm{n}=36$ & $\mathrm{n}=13$ & $\mathrm{n}=14$ & $\mathrm{n}=12$ & $\mathrm{n}=34$ & $\mathrm{n}=37$ & $\mathrm{n}=17$ \\
\hline \multicolumn{9}{|c|}{ \% of sample with specified interpregnancy interval } \\
\hline \multicolumn{9}{|c|}{ Maternal age (Years) } \\
\hline $15-19$ & 43.2 & 22.2 & 7.7 & 0.0 & 16.6 & 0.0 & 2.7 & 0.0 \\
\hline $20-29$ & 35.1 & 44.4 & 46.1 & 50.0 & 58.3 & 58.8 & 62.1 & 5.8 \\
\hline $30-39$ & 18.9 & 25.0 & 38.4 & 42.8 & 25.0 & 38.2 & 32.4 & 94.1 \\
\hline $40-50$ & 2.7 & 8.3 & 7.7 & 7.1 & 0.0 & 2.9 & 2.7 & 0.0 \\
\hline \multicolumn{9}{|l|}{ Gravid } \\
\hline $2-3$ & 64.8 & 69.4 & 23.0 & 35.7 & 50.0 & 55.8 & 78.3 & 23.5 \\
\hline $4-5$ & 27.0 & 11.1 & 61.5 & 35.7 & 41.6 & 20.5 & 13.5 & 29.4 \\
\hline$\geq 5$ & 8.1 & 19.4 & 15.4 & 28.5 & 8.3 & 23.5 & 8.1 & 47.1 \\
\hline \multicolumn{9}{|c|}{ Education Level } \\
\hline None & 59.4 & 62.1 & 69.2 & 42.8 & 41.6 & 61.7 & 54.0 & 41.1 \\
\hline Up to 9 & 24.3 & 24.3 & 15.3 & 42.8 & 33.3 & 32.3 & 37.8 & 17.6 \\
\hline $10-12$ & 16.2 & 11.1 & 15.3 & 14.2 & 25.0 & 2.9 & 5.4 & 29.4 \\
\hline$\geq 13$ & 0.0 & 0.0 & 0.0 & 0.0 & 0.0 & 2.9 & 2.7 & 11.7 \\
\hline \multicolumn{9}{|c|}{ Antenatal care visits } \\
\hline None & 72.9 & 66.6 & 61.5 & 64.2 & 83.3 & 61.7 & 70.2 & 64.7 \\
\hline $1-2$ & 21.6 & 25.0 & 15.3 & 28.5 & 16.6 & 32.3 & 24.3 & 35.2 \\
\hline $3-4$ & 5.4 & 8.3 & 15.3 & 7.1 & 0.0 & 5.8 & 5.4 & 0.0 \\
\hline$\geq 5$ & 0.0 & 0.0 & 7.7 & 0.0 & 0.0 & 0.0 & 0.0 & 0.0 \\
\hline \multicolumn{9}{|c|}{ Socio-economic status } \\
\hline Low & 72.9 & 66.6 & 61.5 & 57.1 & 58.3 & 50.0 & 56.7 & 29.4 \\
\hline Middle & 27.0 & 27.7 & 30.7 & 42.8 & 25.0 & 38.2 & 27.0 & 52.9 \\
\hline High & 0.0 & 5.5 & 7.7 & 0.0 & 16.6 & 11.7 & 16.2 & 17.6 \\
\hline \multicolumn{9}{|l|}{ Residence } \\
\hline Urban & 29.7 & 30.5 & 30.7 & 64.2 & 25.0 & 44.1 & 34.2 & 35.2 \\
\hline Rural & 70.2 & 69.4 & 69.2 & 35.7 & 75.0 & 55.8 & 56.7 & 64.7 \\
\hline
\end{tabular}

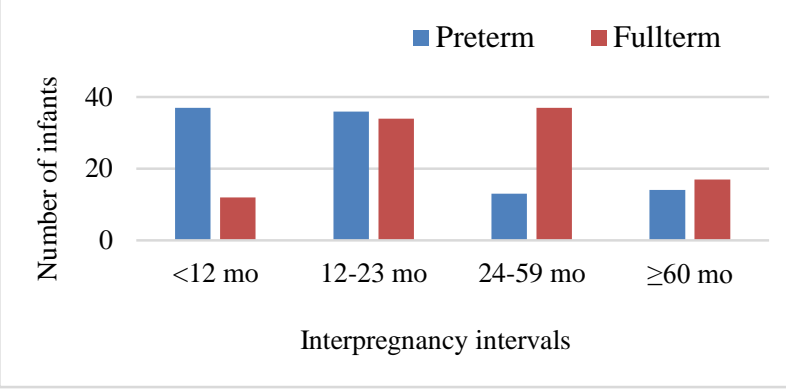

Figure 1: Distribution of preterm (Cases)/term (Controls) infants by interpregnancy intervals.
In Table 2, selected maternal characteristics were evaluated in relation to birth spacing. Compared with women who gave birth to full term neonates, women who gave birth of premature infants were less educated $(60 \%$ vs $53 \%)$, more socioeconomically deprived $(67 \%$ vs $50 \%$ ), and rural residence (65\% vs $60 \%$ )irrespective of birth spacing. Seventy three percent of preterm were born to women with less than optimal birth spacing, of them about 2/3 with no antenatal care, low socioeconomic, and were rural residence. Maternal age $<20$ years was observed in high proportion $(43.2 \%)$ among cases with IPI $<12$ months compared to $16.6 \%$ in controls. 
Table 3 shows the odds ratio associated with selected maternal characteristics for lower IPI groups versus referent group. While IPI of $<12$ months was found significantly associated with the risk for premature birth. The risk was higher in association with 1-2 visits of antenatal $\operatorname{care}(\mathrm{OR}=10,95 \% \mathrm{CI}=1.62-61.46, \mathrm{p}=0.018)$, younger women's age $(\mathrm{OR}=8,95 \% \quad \mathrm{CI}=1.35-8.4$, $\mathrm{p}=0.001)$ in non-educated mother $(\mathrm{OR}=7.92,95 \%$
$\mathrm{CI}=2.49-25.22, \mathrm{p}=0.002)$, gravid $2-3 \quad(\mathrm{OR}=6.5,95 \%$ $\mathrm{CI}=5.06-53.8, \mathrm{p}=0.001$ ), and significant risk was also observed among rural $(\mathrm{OR}=6.60,95 \% \mathrm{CI}=2.46-17.67$, $\mathrm{p}=0.001)$ more than in urban $(\mathrm{OR}=6.21,95 \% \mathrm{CI}=1.45-$ 26.43, $\mathrm{p}=0.012$ ) mothers. As well as among low and intermediate socioeconomic status $(\mathrm{OR}=6.27,95 \%$ $\mathrm{CI}=2.21-17.7, \mathrm{p}=0.004$ and $\mathrm{OR}=6.33,95 \% \mathrm{CI}=1.41-$ $28.39, \mathrm{p}=0.018$ respectively).

Table 3: The Odds ratio of selected maternal characteristics for preterm birth in relation to pregnancy interval.

\begin{tabular}{|c|c|c|c|c|c|c|}
\hline \multirow{2}{*}{ Variables } & \multicolumn{3}{|c|}{$<12$ months } & \multicolumn{3}{|c|}{ 12-23 months } \\
\hline & OR & $95 \% \mathrm{CI}$ & $\mathrm{P}$ & OR & $95 \% \mathrm{CI}$ & $\mathrm{P}$ \\
\hline \multicolumn{7}{|c|}{ Maternal age (years) } \\
\hline $15-19$ & 8.0 & $(1.35-8.4)$ & 0.001 & - & - & - \\
\hline $20-29$ & 3.43 & $(1.09-10.72)$ & 0.029 & 1.47 & $(0.57-3.79)$ & 0.48 \\
\hline $30-39$ & 5.94 & $(1.29-27.2)$ & 0.025 & 1.76 & $(0.58-5.29)$ & 0.397 \\
\hline $40-50$ & - & - & - & 1.5 & $(0.05-40.63)$ & 0.714 \\
\hline \multicolumn{7}{|l|}{ Gravid } \\
\hline $2-3$ & 6.5 & $(5.06-53.8)$ & 0.001 & 5.43 & $(2.05-14.4)$ & 0.007 \\
\hline $4-5$ & 1.54 & $(0.39-5.95)$ & 0.735 & 0.43 & $(0.10-1.93)$ & 0.465 \\
\hline$>5$ & 5.5 & $(0.46-65.1)$ & 0.272 & 1.6 & $(0.38-6.64)$ & 0.719 \\
\hline \multicolumn{7}{|c|}{ Education level } \\
\hline None & 7.92 & $(2.49-25.22)$ & 0.002 & 1.97 & $(0.83-4.68)$ & 0.091 \\
\hline Up to 9 & 4.78 & $(1.12-20.32)$ & 0.040 & 1.74 & $(0.51-5.87)$ & 0.537 \\
\hline$\geq 10$ & 5.0 & $(0.82-30.4)$ & 0.102 & 5.0 & $(0.64-39.1)$ & 0.161 \\
\hline \multicolumn{7}{|c|}{ Antenatal care visits } \\
\hline None & 5.87 & $(2.32-14.82)$ & 0.001 & 2.48 & $(1.09-5.65)$ & 0.04 \\
\hline $1-2$ & 10.0 & $(1.62-61.46)$ & 0.018 & 2.05 & $(0.56-7.45)$ & 0.34 \\
\hline$\geq 3$ & - & - & - & 0.75 & $(0.06-8.83)$ & 0.65 \\
\hline \multicolumn{7}{|c|}{ Socio-economic status } \\
\hline Low & 6.27 & $(2.21-17.7)$ & 0.004 & 2.29 & $(0.95-5.53)$ & 0.08 \\
\hline Middle & 6.33 & $(1.41-28.39)$ & 0.018 & 1.46 & $(0.47-4.50)$ & 0.57 \\
\hline High & - & - & & 4.5 & $(0.31-65.2)$ & 0.517 \\
\hline \multicolumn{7}{|l|}{ Residence } \\
\hline Urban & 6.21 & $(1.45-26.43)$ & 0.012 & 1.24 & $(0.43-3.50)$ & 0.790 \\
\hline Rural & 6.60 & $(2.46-17.67)$ & 0.001 & 3.01 & $(1.26-7.15)$ & 0.018 \\
\hline
\end{tabular}

OR: Odds Ratio, CI: Confidence Interval

\section{DISCUSSION}

There is well documented evidence to link short IPI to adverse perinatal outcomes, including in particular the increased risk of preterm births, therefore appropriate birth spacing has been recommend to achieve favourable outcomes. ${ }^{7,17}$ To our knowledge this is the first study of its type investigating the association of short IPI with preterm births in Yemen. The study showed that women who conceived after a short IPI of less than 24 months after a live birth had a high risk of preterm birth and the highest risk was seen among those with $<12$ months birth interval. Short birth spacing was shown to be significantly confounded by younger maternal age, lack of antenatal care, low education level and 2-3 gravid. The result of this study is in corresponding with data reported from other countries in the region such as UAE, Sudan and Qatar. ${ }^{18-20}$

In Yemen, approximately $54 \%$ of population live under the poverty line and survive on fewer than 2 dollars per day, with about two thirds of the population live in rural areas where health care are limited and of poor quality. ${ }^{21}$ The importance of maternal education as one of the key determinants for maternal and child health is well recognized. ${ }^{22}$ In our population illiteracy rate is high among females in rural $(62 \%)$ as well as urban (54\%) settings. ${ }^{23}$ Available antenatal care was poorly utilized and a single visit for this purpose was noted among $47 \%$ and only $13.9 \%$ of women had four visits in approximate. 
Therefore, it is obviously that the effect of these confounding factors cannot be marginalized, and their influence is interrelated and interdependent.

In our study, $43 \%$ of women were adolescent and gave birth to premature babies in their 2nd or 3rd pregnancy within< 12 moths IPI, but whether adolescent pregnancy or the short IPI is the sole factors contributing to premature birth, is a question remains to be answered in this setting. However, numerous studies from developed as well as developing countries have consistently reported that teenage pregnancy were at increased risk for preterm birth, Yemen, like other developing countries, most women begin their childbearing life early during adolescence, before reaching their full biologic and social maturity. ${ }^{24-26}$

Antenatal care plays an important role in the women's reproductive health, primarily through caring for pregnant women and monitoring pregnancy course facilitating early detection of obstetric complications. It is also addressing other reproductive health needs, such as family planning and provides contraceptive aids. In Yemen the primary health care centers in rural areas are scarce and remote from women's household, and the available centers are inadequately equipped and are running by under qualified persons, which could explain the underutilization of antenatal care by mothers in the current report. $^{26}$

Strict optimal IPI has not been agreed upon universally, but 18-59 months interval was a period found to be associated with lowest risk of preterm birth and our result of 24-59 months IPI is within the same reported limit and in consistent with other studies. $7,8,13,27$

Some studies found that longer IPI ( $\geq 60$ months) was also a risk factor for preterm birth but we did not identify such relationship and our finding is similar to that reported by other researchers. ${ }^{13,18,28,29}$ However, in current study a small number of participants in this age band could be a potential explanation.

Some limitations of this study worth to be mentioned. Although our results are in corresponding with other similar studies based on population surveys, comparison should be taken cautiously, as our sample size is relatively small, the study is a hospital based and preterm births were not phenotypically subdivided to early and late as adverse effect is increase with decrease of gestational age. ${ }^{30}$ Some other confounding factors were not included in the current analysis such as smoking, Qat chewing habit, uses of contraception and lactation practice.

A strength of this study is the inclusion only of mother with former healthy full term infant as women with history of prior preterm birth have a higher tendency to deliver prematurely in a subsequent pregnancies, in addition primigravida women have a higher risk of preterm birth and other adverse outcomes, therefore they were exclude. ${ }^{9,28}$

\section{CONCLUSION}

Our findings, in conjunction with those of other studies on the relationship between IPI and preterm birth, strongly suggest that a short IPI is an important risk factor, and this can be used to support actions targeting improvement of primary health care for pregnant women and addressing the importance of spacing between births.

The rate of preterm birth can be partly reduced by increase birth spacing and delay a second pregnancy through better access to female counselling, contraceptive care and promotion of breast feeding. Women, particularly those who are in adolescent age, are not educated, and from low income families; should be advised about the potential risk and consequences of having premature infant after a short IPI and the benefits of ideal birth interval.

\section{Funding: Not required}

Conflict of interest: None declared

Ethical approval: The study was approved by the Institutional Ethics Committee

\section{REFERENCES}

1. Platt MJ. Outcomes in preterm infants. Public Health. 2014;128:399-403.

2. Smid MC, Stringer EM, Stringer JS. A Worldwide Epidemic: The Problem and Challenges of Preterm Birth in Low- and Middle-Income Countries. Am J Perinatol. 2016;33(3):276-89.

3. Blencowe H, Cousens S, Chou D, Oestergaard M, Say L, Moller AB, et al. Born too soon: the global epidemiology of 15 million preterm births. Reprod Health. 2013;10 Suppl 1:S2.

4. Frey HA, Klebanoff MA. The epidemiology, etiology, and costs of preterm birth. Semin Fetal Neonatal Med. 2016;21(2):68-73.

5. Goldenberg RL, Culhane JF, Iams JD, Romero R. Epidemiology and causes of preterm birth. Lancet. 2008;371:75-84.

6. Simmons LE, Rubens CE, Darmstadt GL, Gravett MG. Preventing preterm birth and neonatal mortality: exploring the epidemiology, causes, and interventions. Semin Perinatol. 2010;34:408-15.

7. Conde-Agudelo A, Rosas-Bermudez A, KafuryGoeta AC. Birth spacing and risk of adverse perinatal outcomes: a meta-analysis. JAMA. 2006;295:1809-23.

8. Hsieh TT, Chen SF, Shau WY, Hsieh CC, Hsu JJ, Hung TH. The impact of interpregnancy interval and previous preterm birth on the subsequent risk of preterm birth. J Soc Gynecol Investig. 2005;12:2027. 
9. Colicchia LC, Simhan HN. Optimizing Subsequent Pregnancy Outcomes for Women with a Prior Preterm Birth. Am J Perinatol. 2016;33(3):267-75.

10. DeFranco EA, Stamilio DM, Boslaugh SE, Gross GA, Muglia LJ. A short interpregnancy interval is a risk factor for preterm birth and its recurrence. Am J Obstet Gynecol. 2007;197:264 e1-6.

11. WHO: Report of a WHO Technical Consultation on Birth Spacing. In. Geneva, Switzerland; 2005.

12. Haq A, Lallar M, Akhter S, Baba Y, Ahmed J, Hamid M. Interpregnancy interval raise odds of adverse perinatal outcome in high fertility region Mewat, Haryana. Int J Reprod Contrasept Obstet Gynecol. 2014;3:598-603.

13. Fuentes-Afflick E, Hessol NA. Interpregnancy interval and the risk of premature infants. Obstet Gynecol. 2000;95:383-90.

14. Winkvist A, Rasmussen KM, Habicht JP. A new definition of maternal depletion syndrome. Am J Public Health. 1992;82:691-4.

15. van Eijsden M, Smits LJ, van der Wal MF, Bonsel GJ. Association between short interpregnancy intervals and term birth weight: the role of folate depletion. Am J Clin Nutr. 2008;88:147-53.

16. Khoshnood B, Lee KS, Wall S, Hsieh HL, Mittendorf R. Short interpregnancy intervals and the risk of adverse birth outcomes among five racial/ethnic groups in the United States. Am J Epidemiol. 1998;148:798-805.

17. Hussaini KS, Ritenour D, Coonrod DV. Interpregnancy intervals and the risk for infant mortality: a case control study of Arizona infants 2003-2007. Matern Child Health J. 2013;17:646-53.

18. Al-Jasmi F, Al-Mansoor F, Alsheiba A, Carter AO, Carter TP, Hossain MM. Effect of interpregnancy interval on risk of spontaneous preterm birth in Emirati women, United Arab Emirates. Bull World Health Organ. 2002;80:871-5.

19. Adam I, Ismail MH, Nasr AM, Prins MH, Smits LJ. Low birth weight, preterm birth and short interpregnancy interval in Sudan. J Matern Fetal Neonatal Med. 2009;22:1068-71.

20. Bener A, Mohmmed S, Khalil S, Basma B, Sharen J, Nancy $S$ et al. The impact of interpregnancy interval on birth weight and other pregnancy outcomes. Rev Pras Saude Mater Infant. 2012;12:233-41.

21. UNICEF/MoPIC/Yemen: Situation analysis of Children in Yemen 2014. In.; 2014.

22. Gakidou E, Cowling K, Lozano R, Murray CJ. Increased educational attainment and its effect on child mortality in 175 countries between 1970 and 2009: a systematic analysis. Lancet. 2010;376:95974.

23. MoE/Yemen: National Report on Adult Education Programs in the Republic of Yemen for the Sixth International Conference on Adult Education (Confintea VI), Brazil, May 2009. In.; 2009.

24. Chen XK, Wen SW, Fleming N, Demissie K, Rhoads GG, Walker M. Teenage pregnancy and adverse birth outcomes: a large population based retrospective cohort study. Int $\mathrm{J}$ Epidemiol. 2007;36:368-73.

25. Khashan AS, Baker PN, Kenny LC. Preterm birth and reduced birthweight in first and second teenage pregnancies: a register-based cohort study. BMC Pregnancy Childbirth. 2010;10:36.

26. Zupan J. Perinatal mortality in developing countries. N Engl J Med. 2005;352:2047-8.

27. Fallahzadeh H, Farajpour Z, Emam Z. Duration and determinants of birth interval in Yazd, Iran: a population study. Iran J Reprod Med. 2013;11:37984.

28. Zhu BP, Rolfs RT, Nangle BE, Horan JM. Effect of the interval between pregnancies on perinatal outcomes. N Engl J Med. 1999;340:589-94.

29. Orji EO, Shittu AS, Makinde ON, Sule SS. Effect of prolonged birth spacing on maternal and perinatal outcome. East Afr Med J. 2004;81:388-91.

30. Marlow N. Full term; an artificial concept. Arch Dis Child Fetal Neonatal Ed. 2012;97:F158-9.

Cite this article as: Bukair AZ, Al-Saqladi AM, AlSadeeq AH. Interpregnancy interval and the risk of preterm birth: a case-control study of infants born at Al-sadaqa general teaching hospital, Aden, Yemen. Int J Reprod Contracept Obstet Gynecol 2016;5:1181-6. 